Nig. J. Biotech. Vol. 37(2): 74-83 (Dec. 2020)

ISSN: 01891731

Available online at

http://www.ajol.info/index.php/njb/index

and www.biotechsocietynigeria.org

DOI: https://dx.doi.org/10.4314/njb.v37i2.7

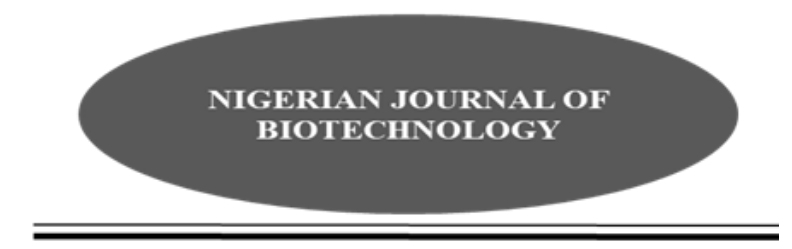

\title{
Optimization of Phytosynthesis of Magnesium Oxide and Magnesium Chloride Nanoparticles
}

\author{
Shittu H. 0.1,2, Igiehon E. 1,2*, Eremwanarue A. 0.1, Oijagbe R. E. ${ }^{1,2}$, Momoh M. \\ $0 .{ }^{1,2}$ and Agbontian M. A. ${ }^{1,2}$ \\ ${ }^{1}$ Department of Plant Biology and Biotechnology, University of Benin, Benin City, Nigeria. \\ ${ }^{2}$ Solution Biotechnology Laboratory, Benin City, Nigeria. \\ ${ }^{3}$ Molecular Unit, Lahor Research Laboratory, Benin City, Nigeria.
}

\begin{abstract}
In the present study, magnesium oxide $(\mathrm{MgO})$ and magnesium chloride $(\mathrm{MgCl})$ nanoparticles were phytosynthesized. Selected parameters like leaf extracts from Moringa oleifera, Vernonia amygadalina and Occimum gratissimum, time of reaction, precursor salts of magnesium oxide and magnesium chloride at varying concentrations, plant extracts to precursor salts volume ratio, $\mathrm{pH}$ of the medium and light sources were optimized for a better production of the nanoparticles. The phytosynthesized $\mathrm{MgO}$ and $\mathrm{MgCl}$ nanoparticles were characterized using UV- Vis spectroscopy technique. The study revealed that the leaf extracts of Moringa oleifera and Vernonia amyg dalina yielded more nanoparticles; the period of 24 hours incubation was enough time for nanoparticles formation and the 0.1 and 0.01 molar concentrations of the precursor salts gave optimal yields of the nanoparticles. The plant extracts at ratio two (2) to precursor salt solution at ratio three (3) resulted in better yield of the nanoparticles; the alkaline pH of 9 and 11 gave better nanoparticles synthesis and the visible light source and dark room environments were better exposure conditions for the nanoparticles formation.
\end{abstract}

Keywords: Leaf extracts, Magnesium chloride nanoparticles, Magnesium oxide nanoparticles, Phytosynthesis, UV- Vis spectroscopy.

Correspond ing author: evansigiehon@gmail.com Introduction

Nanoparticles (NPS) are particles of the size of nanometers or $10^{-9}$ in diameter with distinctive chemical, physical and biological properties (Gul et al., 2014). They are synthesized by physical, chemical and biological methods (Khan et al., 2017; Ahmed et al., 2016). The chemical and physical methods widely utilized for nanoparticles production have huge limitations as they are expensive, they require high pressures/ temperatures, require complex reactions and the process is hazardous through liberations of toxic chemicals which are harmful to the environment

(Ali et al., 2017; Khandelwa and Joshi, 2018). Biological method of nanoparticles synthesis has become an alternative to the conven tional physical and chemical methods (Ahmed et al., 2016; Khandelwa and Joshi, 2018). The biological method involves the use of living organisms such as bacteria, fungi, algae, plants and plant extracts to produce nanoparticles (Rathore and Tarafdar 2015; Obiazikwor and Shittu, 2018). The biological synthesis of nanoparticles using plant materials/ extracts known as phytosynthesis or green synthesis offers additional advantages such as the ease of maintenance and reproducibility 
compared to using microorganisms (Ahmed et al., 2016; Ali et al., 2017); easily scaled up for large scale synthesis and its unique ability for the production of precise shape and controlled structures (Prakash et al., 2013). The yield of NPs synthesized using biological means is reported to be affected by certain conditions (Rathore and Tarafdar 2015). Hence, the need to optimize green synthesis of metallic nanoparticles using selected parameters. Researchers reported that phytochemicals in plant extracts such as proteins, polysaccharides, organic acid, vitamins, as well as secondary metabolites, such as flavonoids, alkaloids, polyphenols, terpenoids and heterocyclic compounds have significant roles in metal salt reduction and furthermore, act as capping and stabilizing agents for the synthesized nanoparticles (Ahmed et al., 2016; Saranya et al., 2017). Extracts of some plants like Ocimum teniflorum, Solanum tricobatum, Punica granatum, Centella assiatica, Citrus sinensis Brassica oleracea, Citrus lemon, Nephelium lappaceum, Swertia chirayatia, Artemisia abrotanum, Clitoria sp, Trignella foenumgraecum, , Carica papaya and Tridax procubem have been reported to be used for the synthesis of metallic nanoparticles (Sharma et al., 2017; Vergheese and Vishal 2017; Dobrucka et al., 2018). Magnesium oxide nanoparticles (MgO NPs) are highly ionic nanoparticulate metal oxides with unique properties due to its high surface area and characteristic unusual crystal morphologies (Vergheese and Vishal 2017 Dobrucka 2018). MgO NPs have wide applications in various areas (Sharma et al., 2017; Dobrucka 2018). From literature review, the application of phytosynthetic means to obtain $\mathrm{MgO}$ NPs and $\mathrm{MgCl}$ NPs has not been fully explored, which presents research opportunities. In this study, the synthesis of the NPs was done using the leaves extracts of Moringa oleifera, Ocimum gratissimum and Vernonia amygdalina. The plant Vernonia amygdalina belongs to the family Asteraceae; Moringa oleifera Lam (syn. M. ptreygosperma Gaertn.), species of a monogeneric family Moringaceae; Ocimum gratissimum belongs to the Lamiaceae family. The leaves of these plants contain important bioactive constituents such as alkaloids, tannins, flavonoids, saponins, glycosides and phenolic compound (Aja et al., 2014; Alemayehu and
Serawit 2014; Shittu et al., 2016; Shuaibu and Shuaibu, 2017; Bhavani et al., 2019). This study aims at optimizing the phytosynthesis of $\mathrm{MgO}$ NPs and MgCl NPs for better yields.

\section{Materials and methods}

Plant materials

Moringa oleifera (moringa leaf), Occimum gratissimum (scent leaf) and Vernonia amygalina (bitter leaf) were used for this study and they were obtained from residential quarters at Uteh in Benin City, Edo State, Nigeria. The plants were identified and authenticated by a plant taxonomist at the Department of Plant Biology and Biotechnology, University of Benin.

\section{Chemical precursors}

Magnesium oxide $(\mathrm{MgO})$ and magnesium chloride hexahydrate $\left(\mathrm{MgCl}_{2} \cdot 6 \mathrm{H}_{2} \mathrm{O}\right)$ were used as precursor salts, along with other necessary chemicals. These chemicals were purchased from Pyrex suppliers, Benin City, Edo State, Nigeria.

\section{Preparation of plant extracts}

Healthy fresh leaves of Moringa oleifera, Vernonia amygadaina, and Occimum gratissimun were collected. The leaves were thoroughly washed with tap water to remove soil and any form of dirt and finally rinsed with distilled water. The leaves were cut into small pieces and 20 grams each were respectively taken into a $250 \mathrm{ml}$ Erlenmeyer flask containing $100 \mathrm{ml}$ sterile distilled water and kept in a water bath at $100{ }^{\circ} \mathrm{C}$ for 10 minutes. The extracts were filtered using Muslin cloth and Whatman filter paper No. 1 to obtain the aqueous plant extracts.

\section{Preparation of precursor solutions}

Magnesium oxide and magnesium chloride precursor solutions were prepared in molar concentration. The concentrations of $0.1 \mathrm{M}, 0.01$ $\mathrm{M}$ and $0.001 \mathrm{M}$ magnesium oxide ( $\mathrm{MgO}$ ) aqueous solution were prepared by dissolving $0.4 \mathrm{~g}, 0.04$ $\mathrm{g}$ and $0.004 \mathrm{~g}$ of precursor salt of magnesium oxide in $100 \mathrm{ml}$ double distilled water, respectively. Similarly, the concentrations of 0.1 $\mathrm{M}, 0.01 \mathrm{M}$ and $0.001 \mathrm{M}$ magnesium chloride $\left(\mathrm{MgCl}_{2}\right)$ aqueous solution was prepared by dissolving $2.01 \mathrm{~g}, 0.203 \mathrm{~g}$ and $0.0203 \mathrm{~g}$ of precursor salt of magnesium chloride in $100 \mathrm{ml}$ double distilled water. These solutions were used 
for the green synthesis of magnesium oxide and magnesium chloride nanoparticles.

\section{Synthesis of magnesium oxide and magnesium chloride nanoparticles}

Magnesium oxide and chloride nanoparticles were synthesized by a method described by Sharma et al., (2017). An aliquot of the leaf extracts $(10 \mathrm{ml})$ of the resulting filtrate was transferred into $30 \mathrm{ml}$ of $0.1 \mathrm{M} \mathrm{MgO}$ and $\mathrm{MgCl}_{2}$ solutions, respectively. These were incubated for 24 to 48 hours at $28 \pm 2^{\circ} \mathrm{C}$. As a result, the solutions developed a brownish colloidal and dark brown appearance, indicating the formation of nanoparticles.

Optimization of magnesium oxide nanoparticles and magnesium chloride nanoparticles synthesis The synthese $s$ of magnesium oxide and magnesium chloride NPs were optimized by varying some conditions of synthesis. The molarity of the precursor salts ( magnesium oxide and magnesium chloride hexahydrate) (98 $\%)^{\prime \prime}$ was varied to ascertain the best molarity for the synthesis of magnesium oxide and magnesium chloride nanoparticles. The molar concentrations of the precursor salts used for this study were $0.1 \mathrm{M}, 0.01 \mathrm{M}$ and $0.001 \mathrm{M}$. The volume ratio of the leaf extracts to precursor salts $(1: 3,2: 3 ; 3: 3)$ were varied to determine the most suitable volume ratio for magnesium oxide and magnesium chloride nanoparticles formation. The $\mathrm{pH}$ of the reaction mixture was optimized, using $\mathrm{pH}$ values of 5.0 (acidic), 7.0 (neutral), 9.0 and 11.0 (alkaline) to investigate the most suitable $\mathrm{pH}$ for a higher yield of NPs. The $\mathrm{pH}$ of the reaction mixture was adjusted using $\quad 0.1 \mathrm{~N} \mathrm{HCL}$ and 0.1 $\mathrm{M} \mathrm{NaOH}$ buffer solutions. Selected light sources such as monochromes (blue, red and green), visible light and dark room were used for magnesium oxide and chloride nanoparticles phytosynthesis to determine the effect of monochromes, visible light and dark room on phyto-assisted nanoparticles production.

\section{Characterization of nanoparticles}

A UV-Vis 1800 double-beam spectrophotometer (Shimadzu, Tokyo, Japan) operating within a range of 250 to $1000 \mathrm{~nm}$ wavelength was used to monitor and confirm the formation of MgO NPs and $\mathrm{MgCl}$ NPs based on their optical properties and the bio-reduction of $\mathrm{Mg}^{2+}$ ions to nanoparticles in the respective solutions. Measurement of the absorbances of the nanoparticles in colloidal solutions at regular intervals of 24 and 48 hours was done by loading each of the samples $(2 \mathrm{ml})$ in quarts cuvette and then placed on the UV-Vis spectrophotometer with absorbance readings ranging from 250 to $600 \mathrm{~nm}$ using a resolution of $1 \mathrm{~nm}$.

\section{Results}

The syntheses of $\mathrm{MgCl}$ NPs and MgO NPs were achieved each using moringa leaf, scent leaf and bitter leaf extracts. When the precursor solution and the leaf extracts were added together, a colour change from pale green to brownish and dark brown colloidal solutions was observed within 24 hours of synthesis at $28 \pm 2^{\circ} \mathrm{C}$. It was observed that when bitter leaf extract was mixed with $\mathrm{MgO}$ precursor solution, the mixture colour change was from pale green to dark brown colloidal solution; when moringa leaf extract was added to MgO precursor solution, the mixture colour change was from pale green to brownish colloidal solution. Similarly, when the test leaf extracts were mixed with $\mathrm{MgCl}$ precursor solution, the mixture colour change was from pale green to dark brown colloidal solution with bitter leaf extract; brownish colloidal solution with moringa leaf extract, respectively. In order to investigate the relationship between yield and absorbance values, the phytosynthesized NPs (100\% concentration) was diluted twice to obtain 50 and $25 \%$ concentrations and spectrophotometric readings were determined. Similar observations were made for both the Abs values obtained for the MgCl NPs and MgO NPs (Fig. 1). 


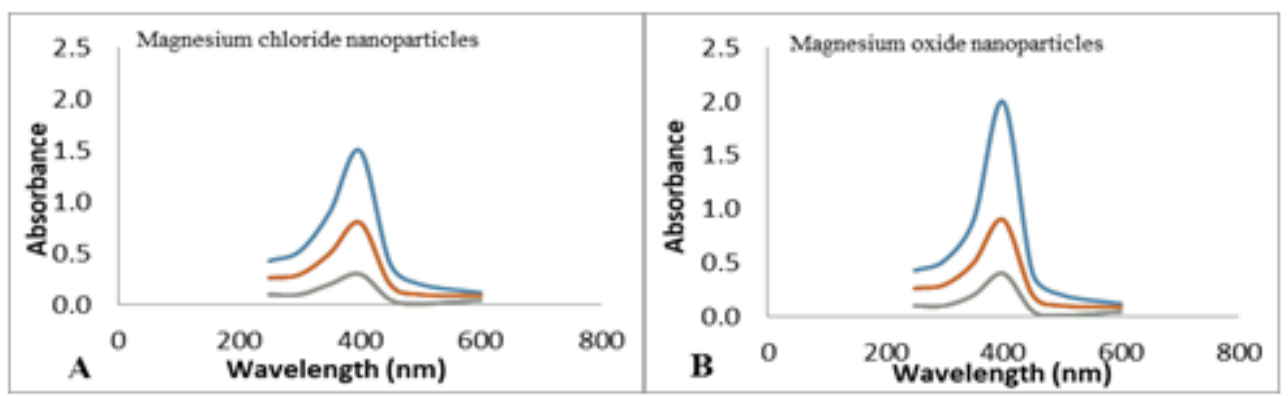

Figure 1: Relationship between Absorbance values and yields of phytosynthesized magnesium chloride and magnesium oxide nanoparticles

The highest Abs values were obtained for the 100 $\% \mathrm{MgCl}$ NPs and MgO NPs (1.6 and 2.1, respectively), followed by the $50 \%$ (0.7 and 0.9 , respectively), while the lowest values ( 0.3 and 0.4 , respectively) were recorded for the $25 \%$ NPs. Maximum Abs values were recorded between the wavelengths of $390-410 \mathrm{~nm}$ with a peak value at $400 \mathrm{~nm}$. The effectiveness of the leaf extracts in NP synthesis was examined. Bitter leaf, Moringa leaf and Scent leaf extracts were respectively used to synthesize MgO NPs and $\mathrm{MgCl} N \mathrm{NP}$; and the Abs values were determined after 24 and 48 hours of synthesis. The results (Fig. 2) obtained indicated that NP synthesis was possible with all the test plant extracts. There was higher yield of MgO NPs synthesized using the bitter leaf and moringa leaf extracts, as indicated by the higher Abs values of 2.1 and 2.0, respectively, compared to the scent leaf extract, which had an Abs value of 1.6. A similar observation was made for the $\mathrm{MgCl}$ NPs synthesized. There was no significant difference in the amount of $\mathrm{MgO} \mathrm{NPs}$ and $\mathrm{MgCl} \mathrm{NPs}$ synthesized after 24 and 48 hours.

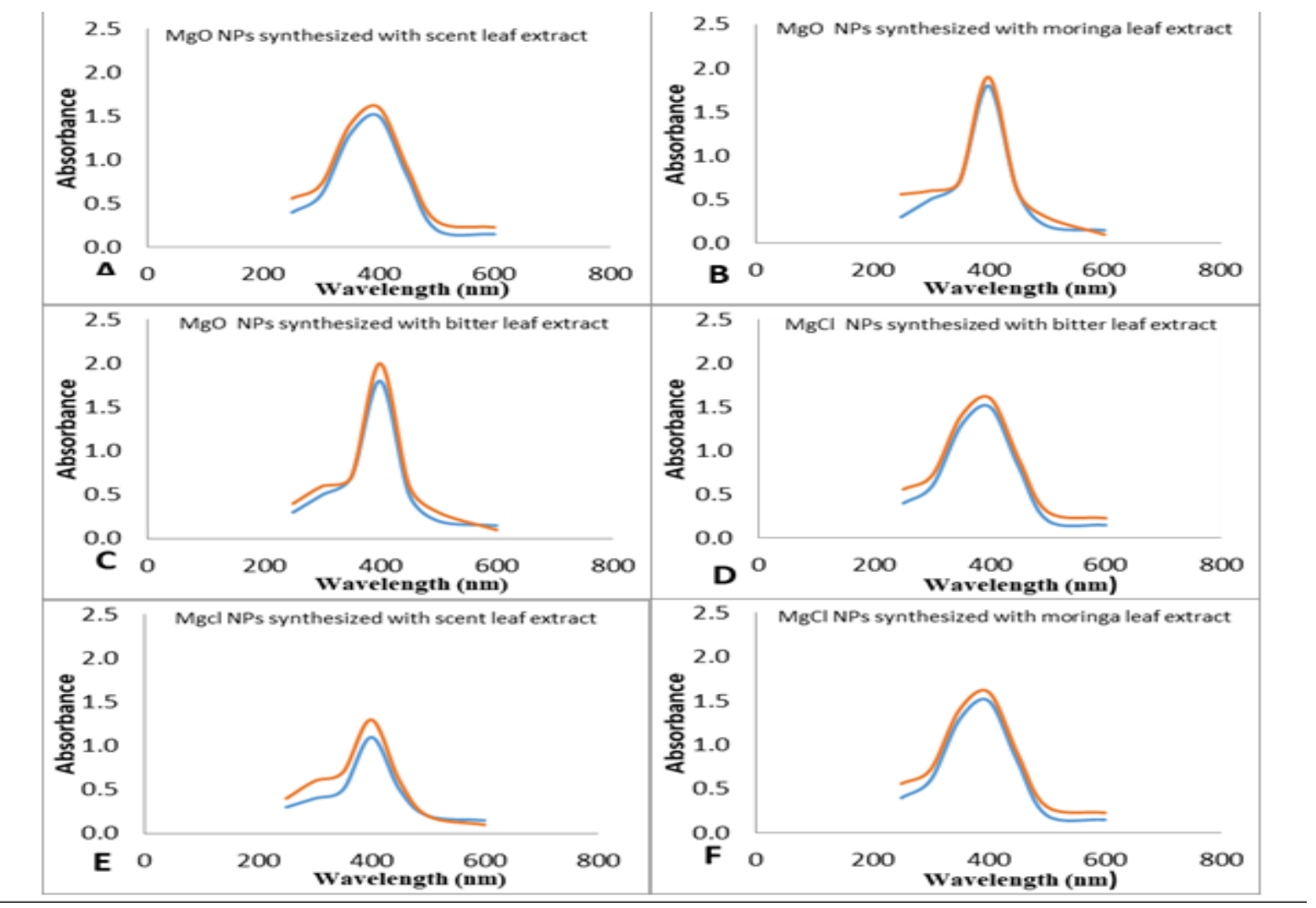


Figure 2: Effect of plant leaf extracts on the yield of magnesium chloride and magnesium oxide nanoparticles obtained after 24 and 48 hours of synthesis.

Table 1: Quantitative analysis of phytochemical components of the leaves aqueous extracts

\begin{tabular}{llll}
\hline Phytochemicals & Moringa leaf & Bitter leaf & Scent leaf \\
& & & \\
\hline Oxalate & 2.98 & 3.48 & 0.75 \\
Phytol & 4.11 & 3.95 & 5.56 \\
Tannins & 10.6 & 9.62 & 2.48 \\
Saponins & 5.95 & 5.97 & 3.52 \\
Flavonoids & 5.01 & 4.89 & 1.74 \\
Glycosides & 3.08 & 1.11 & 2.38 \\
Alkaloids & 3.13 & 2.16 & 1.07 \\
Anthraquinones & 1.45 & 0.14 & 0.31 \\
Steroid & 2.09 & 0.38 & 0.30 \\
Phenol & 4.04 & 3.24 & 0.73
\end{tabular}

Table 1 shows the results of the phytochemical constituents present in the aqueous extracts of test leaf extracts (moringa leaf, scent leaf and bitter leaf). It was observed that phytochemicals such as phytol, alkaloids, steroid, flavonoids, terpenoids and phenols were present in all the aqueous extracts. Moringa and bitter leaves contain more of the phytochemicals, compared to the scent leaf.

Figure 3 reveals the results of the UV- Vis absorbance values of $0.1,0.01$ and 0.001 molar concentrations of precursor salts (magnesium oxide and magnesium chloride) solutions with bitter and moringa leaves extracts. The optimized precursor salt concentrations at the level of 0.1 $\mathrm{M}, 0.01 \mathrm{M}$ and $0.001 \mathrm{M}$ show that the concentrations of $0.1 \mathrm{M}$ and $0.01 \mathrm{M}$ precursor salt solutions with the plant extracts used for the study gave higher absorption spectra; an indication of higher yield. The results of the absorbance values of phytosynthesized magnesium oxide nanoparticles and magnesium chloride nanoparticles when different ratios of plant extracts to precursor solutions were optimized for better yield of the nanoparticles is shown in Figure 4 . The ratios 1:3 and 2:3 of the plant extracts to precursor solutions gave higher absorbance peaks than the ratio 3:3 of the plant extracts to precursor solution after 24 hours of synthesis. Figure 5 showed the spectrophotometric readings of the different $\mathrm{pH}$ conditions of the mixture of the plant extracts and the precursor solutions for $\mathrm{MgO} \mathrm{NPs}$ and $\mathrm{MgCl}$ NPs synthesis. The results show that the optimization of $\mathrm{pH}$ values from acidic $\mathrm{pH}$ 5, through neutral $\mathrm{pH} 7$ to alkaline $\mathrm{pH} 9$ and more alkaline $\mathrm{pH} 11$ of the mixture significantly affected the formation of both MgO NPs and $\mathrm{MgCl}$ 
NPs. Alkaline $\mathrm{pH}$ of 9 and 11 tend to favour synthesis of the nanoparticles as both $\mathrm{pH}$ of 9 and 11 gave very high absorption spectra, an indication of higher yield of NPs. It was revealed from the results of UV-Vis absorbance of $\mathrm{MgO}$
NPs and $\mathrm{MgCl}$ NPs under different light conditions and dark room (Figure 6) that visible light and dark room conditions gave higher yields compared to the monochromes.

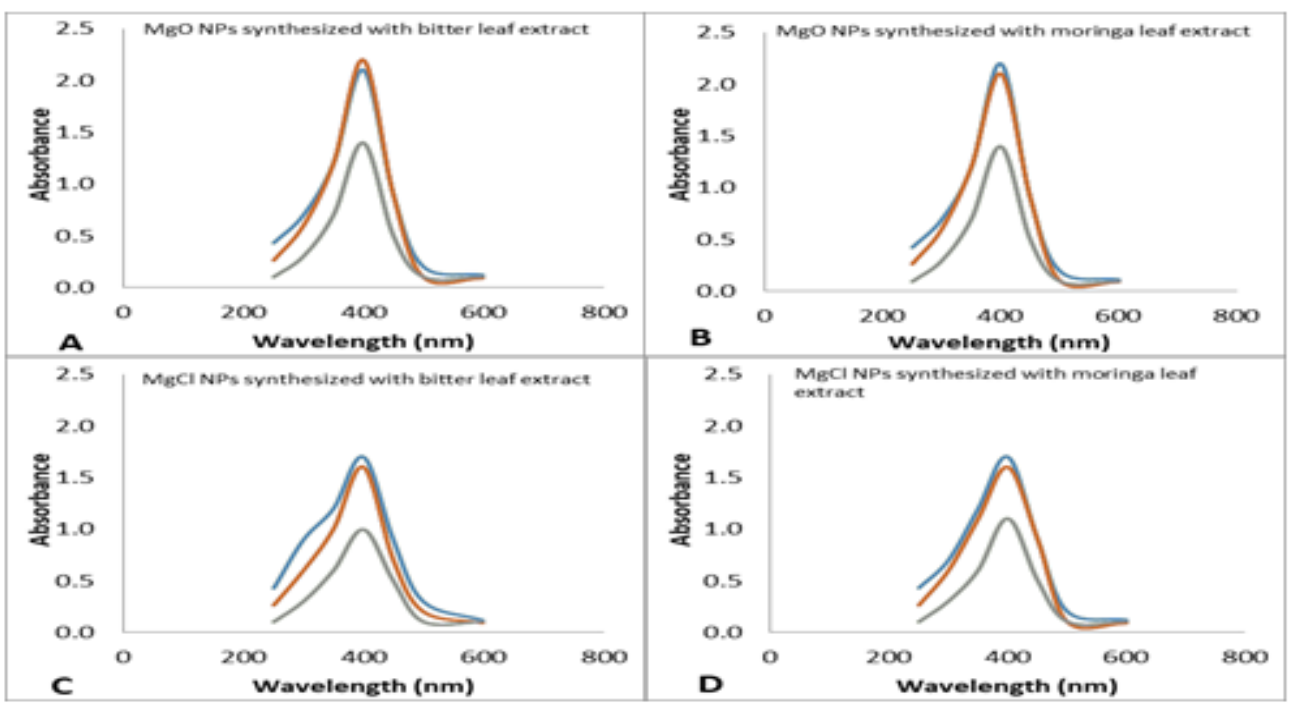

Figure 3: Absorbance readings of magnesium oxide and magnesium chloride nanoparticles synthesized using different conconcentrations of precursor solution

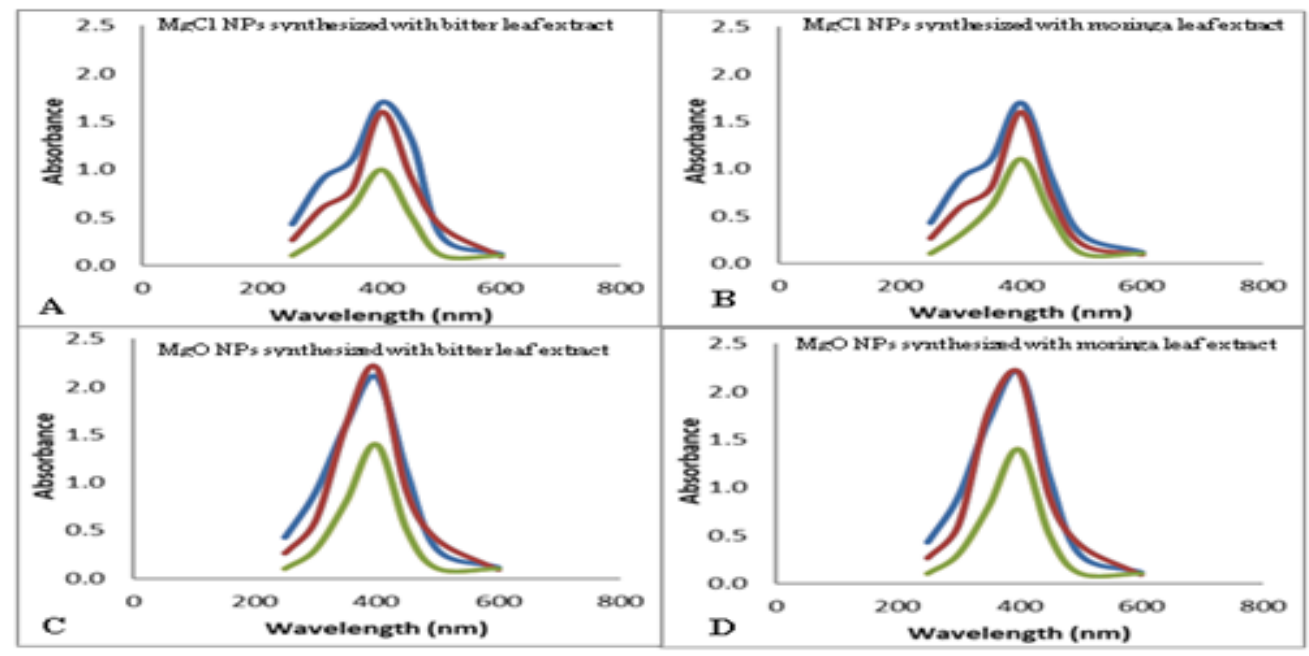

Figure 4: Absorbance values of phytosynthesized $\mathrm{MgO}$ and $\mathrm{MgCl} \mathrm{NPs}$ at varying volume ratio of plant extracts to precursor salt solutions 


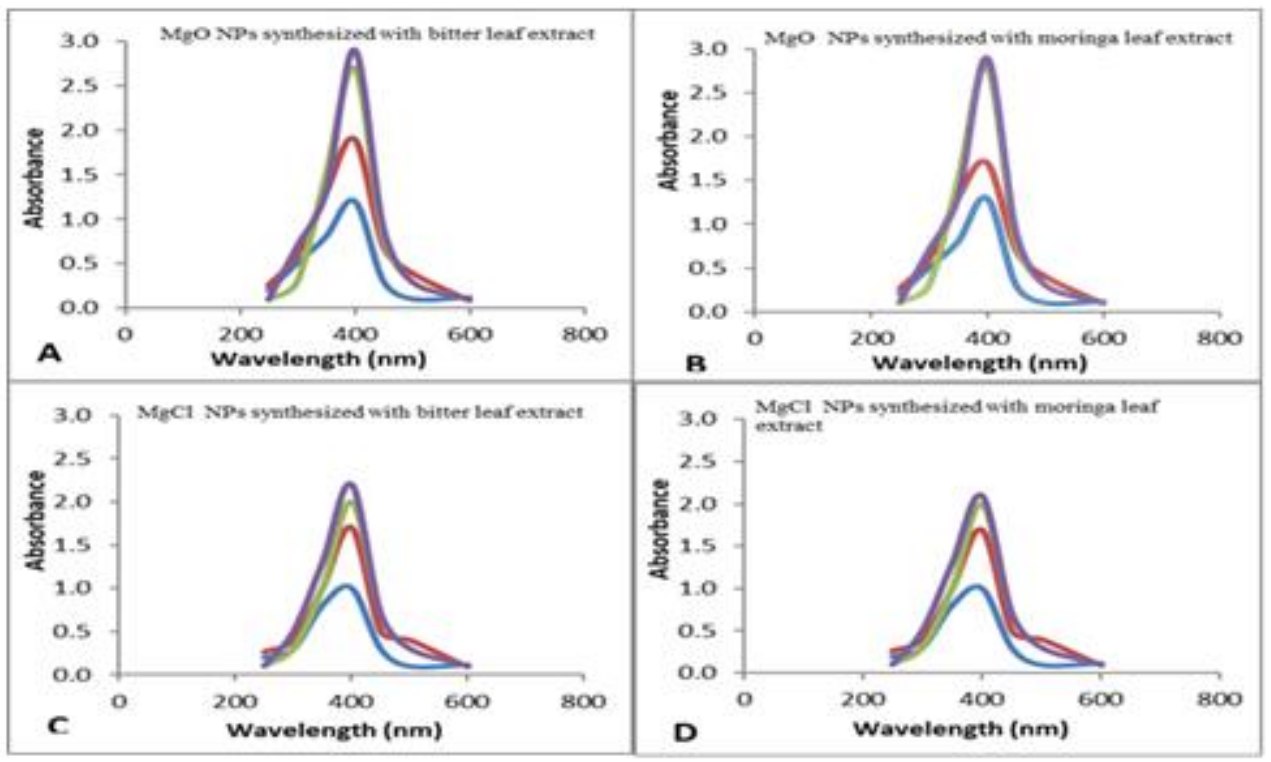

Figure 5: Absorbance readings of the phytosynthesized magnesium chloride and magnesium oxide nanoparticles using different $\mathrm{pH}$ values.
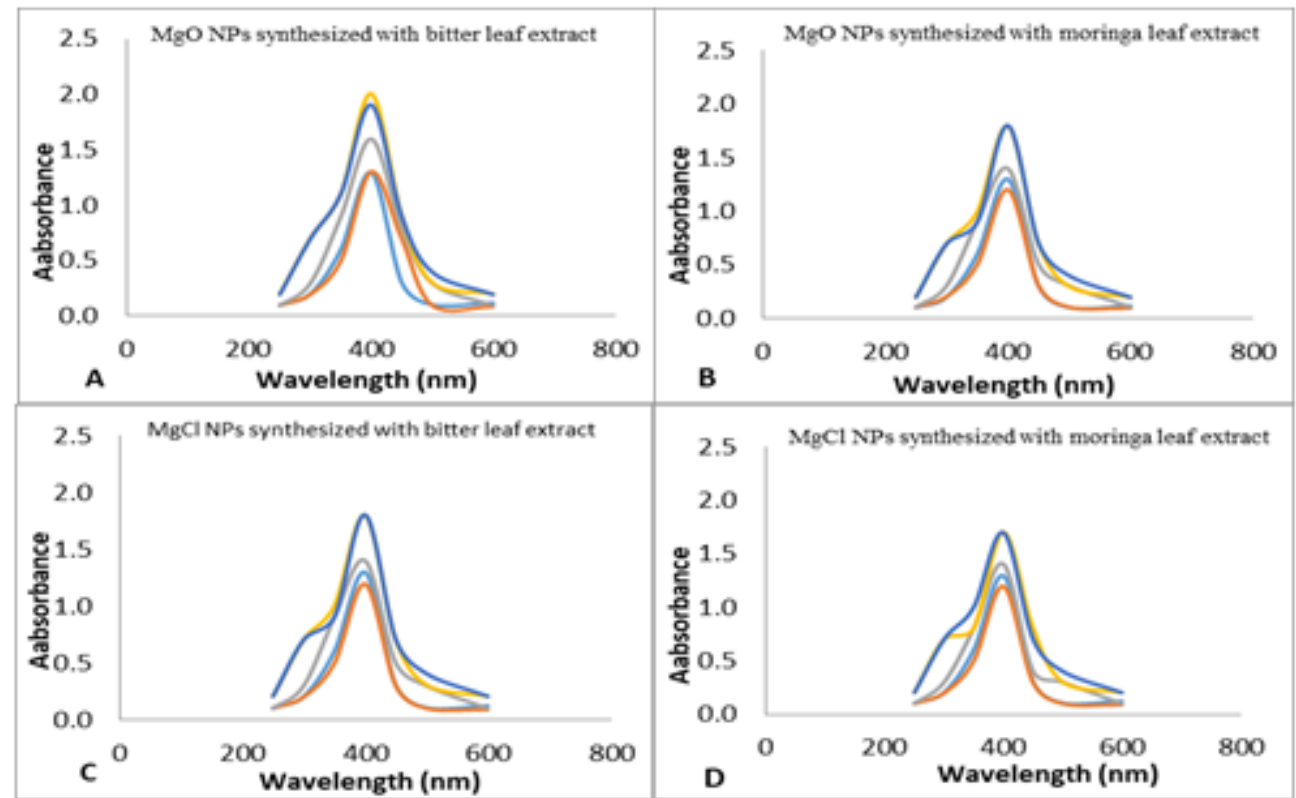

Figure 6: Absobance readings of phytosynthesized magnesium chloride and magnesium oxide nanoparticles using monochromes, visible light and dark chamber.

Light sources: - : Green light; $\quad$-: Red light; $\quad$ : Blue light; $\longrightarrow$ Visible light; $\quad$ : Dark room 


\section{Discussion}

The present study revealed that formations of $\mathrm{MgO}$ nanoparticles and $\mathrm{MgCl}$ nanoparticles were achieved using leaf extracts and magnesium oxide and magnesium chloride precursor solutions within 24 hours at room temperature $\left(28 \pm 2{ }^{\circ} \mathrm{C}\right)$. The colour change with the colloidal appearance of the solutions was a signal of phyto-reduction of the magnesium oxide and magnesium chloride precursor solutions by the aqueous leaves extracts to $\mathrm{MgO}$ nanoparticles and $\mathrm{MgCl}$ nanoparticles, respectively. Spectrophotometric readings of the phytosynthesized MgO NPs and $\mathrm{MgCl}$ NPs at the wavelengths range of $250-600 \mathrm{~nm}$ confirmed the yield of the nanoparticles in the colloidal suspensions prepared at different concentrations of $100 \%, 50 \%$ and $25 \%$ (Fig. 1). The study showed that $100 \%$ concentration of $\mathrm{MgO}$ and $\mathrm{MgCl}$ nanoparticles colloidal solutions have the highest yields of NPs; this was followed by the 50 $\%$ concentration with $25 \%$ concentration having the lowest yield . The study shows that the peak of the absorbance at $400 \mathrm{~nm}$ indicated successful formation of the nanoparticles and the increase in the absorbance peak at $100 \%$ indicated increased yield of the synthesized nanoparticles (Fig. 1). Researchers in some previous works have reported that peak of absorbances within the range of $250-550$ is an indication of nanoparticles synthesis and higher peak of absorbance signifies higher nanoparticles formation (Sharma et al., 2017; Debrucka et al., 2018). According to Abbas (2019), UV-Vis absorption spectroscopy is one of the most widely used techniques for characterizing the optical properties and electronic structure of nanoparticles. It uses visible and adjacent nearUV light to detect the presence of nanoparticles by measuring the absorption of light by a sample at a wavelength range of $250-800 \mathrm{~nm}$, which helps to identify the optical properties of nanoparticles (Haiss et al., 2007; Abbas, 2019). Optical properties of nanoparticles are sensitive to concentration, shape, agglomeration and size, which make this technique, a valuable tool for studying, characterizing and identifying nanoparticles (Haiss et al., 2007). In Fig. 2, the spectrophotometric readings of the phytosynthesized MgO NPs and MgCl NPs using the test plant extracts after 24 and 48 hours of synthesis revealed that bitter and moringa leaves extracts yielded higher amounts of the synthesized NPs. It was also observed that no significant difference in the amounts of MgO NPs and $\mathrm{MgCl}$ NPs synthesized after 24 and 48 hours. The observation indicated that the reduction of magnesium ions took place extracellularly. This mechanism of plant- assisted reduction has been attributed to the presence of phytochemicals such as terpenoids, flavonoids, ketones, phenols, polyphenol, alkaloids aldehydes, amines, steroid and carboxylic acids present in the plants/ plants extracts which act as reducing, capping and stabilizing agents; plant extracts play a significant role in bio-reduction of metallic salts to nanoparticles (Saranya et al., 2017; Sharma et al., 2017). The study revealed that the phytochemical constituents present in the aqueous extracts of the test leaf extracts (Table 1) were responsible for the reduction of magnesium ions to nanoparticles; the higher content of the biomolecules present in both moringa and bitter leaves extracts were responsible for higher $\mathrm{MgCl}$ NPs and MgO NPs formation compared to nanoparticles synthesis using scent leaf (Figure 3). Previous phytochemical composition studies show that moringa oleifera leaves are endowed with immense phytochemicals in high concentrations (Aja et al., 2014; Alemeh and Serawit, 2014). Similarly, Shuaibu and Shuaibu, (2017) reported high phytochemical concentrations in bitter leaf extract. The UV- Vis abs values of $0.1,0.01$ and 0.001 molar concentrations of precursor salts solutions with the test leaf extracts (Fig. 3) revealed that the molar concentrations of 0.1 and 0.01 precursor salt solutions gave more synthesized nanoparticles. Saranya et al. (2017) in an earlier study reported that iron nanoparticles synthesize d using Musa ornata flower sheath extract gives the best yield at optimum precursor salt concentration of $0.01 \mathrm{M}$. It was observed from the current study that the ratio of test plant extracts to precursor salt solutions affected the synthesis of the nanoparticles. The ratios, 1:3 and 2:3 of the plant extracts to precursor solutions gave higher amounts of NPs than the ratio 3:3 after hours of synthesis (Fig. 4). This suggested that the bioreduction of $\mathrm{Mg}^{2+}$ to nanoparticles requires optimum leaf extract concentration. In a previous 
study, Jeevanandam et al., (2017) reported that $1: 3$ ratio of plant extract to precursor solution was a threshold concentration for nanoparticle formation, as higher extract concentration led to less nanoparticle formation. In the present study, the $\mathrm{pH}$ conditions of the mixture of the test plant extracts and the precursor solutions significantly affected the formation of both $\mathrm{MgO}$ NPs and $\mathrm{MgCl}$ NPs (Fig 5) with alkaline $\mathrm{pH}$ of 9 and 11 promoting more and faster synthesis of the nanoparticles. Similarly, Sanghi and Verma, (2009) and Saranya et al. (2017) reported that the green synthesis of silver nanoparticles and iron nanoparticles were proved to be faster at alkaline conditions compared to acidic and neutral conditions; at alkaline conditions there was no need for agitating the mixture for the formation of nanoparticles and all the metallic ions were converted to nanoparticles within an hour. It was further suggested that the alkaline ion $(\mathrm{OH})$ was essential for the reduction of metal ions. The UVVis abs values of MgO NPs and MgCl NPs under different light conditions and dark room (Fig. 6) revealed that nanoparticles formation was better under visible light and dark room conditions. However, studies have shown that some nanoparticles synthesis can either be slow or faster under light conditions; as it was reported that direct sunlight was utilized to reduce the time rate of synthesis of silver nanoparticles using moringa leaf extracts (Moodley et al., 2018).

\section{Conclusion}

Phytosynthesis of magnesium oxide and magnesium chloride nanoparticles were achieved by using magnesium oxide and magnesium chloride precursor salts and leaf extracts as reducing and capping agents. It was established that for optimal synthesis of $\mathrm{MgO}$ and $\mathrm{MgCl} \mathrm{NPs}$, 0.1 and $0.01 \mathrm{M}$ of precursor salt solutions with the leaf extracts at ratio $1: 3$ and 2:3 were more effective. Similarly, it was shown that alkaline medium fast-track nanoparticles formation and visible light and dark environment were better for nanoparticles synthesis. It is worthy of note that phytosynthesis of metallic oxide/chloride nanoparticles facilitates non-toxic, quick, ecofriendly and cheaper means of nanoparticles production.

\section{References}

Abbas, Q. (2019). Understanding the UV- Vis spectroscopy for nanoparticles. J. Nano. Mol. Nanotech. 8: 3-6.

Aja, P. M., Nwachukwu, N., Ibiam, U. A., Igwenyi I. O., Offor, C. E. and Orji, O. U. (2014). Chemical constituents of Moringa oleifera leaves and seeds from Abakaliki. Nig. America J. Phyto. and Clin. Therapeutics, 2(3): 3-10

Alemayehu, T. and Serawit, D. (2014). Phytochemistry and pharmacological activities of moringa oleifer. Inter. J. Pharma. 1(4): 222-23.

Ahmed, R. N., Sani, A., Oluwa, O. N., Sule, I. O and Zakariyah, R. F. (2016). Green synthesis and antibacterial activity of silver nanoparticles from extract of leaves of Croton zambesicus. Nig. J. Microbiol. 30(1): 3192-3199.

Ahmed, S., Ahmed, M., Swami, B. L. and Ikram, S. (2016). A review on plant extract mediated synthesis of silver nanoparticles for antimicrobial applications: A green expertize. J. Adv. Res. 7: 17-28.

Ali, A., Zafar, A., Zia, M., Hag, I. U., Phull, F. R., Ali, J. S. and Hussain, A. (2017). Synthesis, characterization, applications and challenges of iron oxide nanoparticles. Nanotech. Sci. App. 9: 49-67.

Bhavani, T., Rammohan, R., Mounica, C., Nyamisha, J., Gopi Krishna, A., Prabhavathi, P., Ramasubramania, R. R. and Harinadha, B. K. (2019). Phytochemical screening and antimicrobial activity of Ocimum gratissimum review. J. Pharma. Phytochem., 8(2): 76-79.

Dobrucka, R. (2018). Synthesis of MgO Nanoparticles Using Artemisia abrotanum Herba Extract and Their Antioxidant and Photocatalytic Properties. Iran J. Sci. Tech. Tran. Sci. 42: 547555.

Khandelwal, A. and Joshi, R. (2018). "Synthesis of Nanoparticles and their Application in Agriculture". Acta Sci. Agric. 2(3): 10-13.

Gul, H. T., Saeed, S., Khan F. Z. A, and Manzoor S. A. (2014). Potential of Nanotechnology in 
Agriculture and Crop Protection: A Review. App. Sci. and Bus. Eco. 1(2): 23-28.

Haiss, W., Thanh, N. T., Aveyard, J. and Fernig D. G. (2007). "Determination of size and concentration of gold nanoparticles from UV-Vis spectra." Anal. chem. 79 (11):4215-4221.

Jeevanandam J., Chan Y. S. and Danquah M. K. (2017). "Biosynthesis and Characterization of MgO nanoparticles from plant extracts via induced molecular nucleation". New J. Chem. 41:2800- 2814.

Khan, I., Saeed, K. and Khan, I. (2017). Nanoparticles: Properties, applications and toxicities. Arabian J. Chem. http://dx.doi.org/ 10.1016/j.arabjc.2017.05.011

Khandelwal, A. and Joshi, R. (2018). "Synthesis of Nanoparticles and their Application in Agriculture". Acta Sci. Agric. 2(3):10-13.

Moodley, J. S., Krishna, S. B. N., Pillay, K., Govender, S. and Govender, P. (2018). Green synthesis of silver nanoparticles from Moringa oleifera leaf extracts and its antimicrobial potential. Adv. Nat. Sci: Nano. Nanotech. 9: $1-$ 9.

Obiazikwor O. H and Shittu, H .O (2018). Antifungal activity of silver nanoparticles synthesized using Citrus peel extract against fungal phytopathogens isolated from diseased tomato (Solanum lycopersicum L.). I. Biol. Sci. Pharma. Res. 6(3): 30-38

Prakash, P., Gnanaprakasam, P., Emmanuel, R., Arokiyaraj, S. and Saravanan, M. (2013). Green synthesis of silver nanoparticles from leaf extract of Mimusops elengi L. for enhanced antibacterial activity against multi drug resistant clinical isolates. Coll. Surf. B: Biol. 108: 255-259.

Sanghi, R and Verma, P. (2009). Biomimetic synthesis and characterization of protein capped silver nanoparticles. Bio. Tech. 100: 501-504. Saranya, S., Vijayarani, K. and Pavithra, S. (2017). Green synthesis of iron nanoparticles using aqueous extract of musa ornate flower shealth against pathogenic bacterial. In. J. Pharm. Sci. 79(5):688-694.

Sharma, G., Soni, R. and Jasuja, D. N. (2017). Photoassisted synthesis of magnesium oxide nanoparticles with Swertia chirayatia. J. Tai. Uni. Sci. 11:471-477.

Shuaibu, A. S. and Shuaibu, A. B. (2017). Assessment of the phytochemical constituents and in-vitro antibacterial activity of Vernonia amygdalina extracts on someclinical isolates. Pharm. Chem. J. 4(4):123-128

Tarafdar, J. C. and Raliya, R. (2014). Biosynthesis and characterization of zinc, magnesium and titanium nanoparticles: an eco-friendly approach. Inter. Nano. Lett. 4:93-103.

Rathore, I. and Tarafdar, J. C. (2015). Perspective of biosynthesized magnesium nanoparticles in foliar application of wheat plant. J. Bionano. 9:1-6.

Vergheese, M. and Vishal, S. K. (2018). Green synthesis of magnesium oxide nanoparticles using Trigonella graecum leaf extract and its antibacterial activity. J. Pharma. Phytochem. 7(3): 1193-1200. . 